\title{
Penerapan Iptek Bagi Peningkatan Kapasitas Dan Kualitas Guru Tk Di Desa Nyogan Melalui Sistem Pembelajaran Berbasis Multimedia
}

\author{
Wirmie Eka Putra $^{1 *}$, Dedy Setiawan ${ }^{2}$, Yuliusman$^{1}$, Lucky Enggrani Fitri ${ }^{1}$ \\ ${ }^{1}$ Fakultas Ekonomi dan Bisnis, Universitas Jambi, Indonesia \\ ${ }^{2}$ Fakultas Sains dan Teknologi, Universitas Jambi, Indonesia \\ Email Korespondensi: wirmie_eka@unja.ac.id
}

\begin{abstract}
ABSTRAK
Sistem pembelajaran pada anak-anak memiliki system pembelajaran yang berbeda. System pembelajarannya bersifat auditori, visual maupun kinestik. Namun pada umumnya anak lebih tertarik belajar mengunakan metode dengan mengunakan multimedia sebagai medianya dikarenakan dengan cara ini lebih mudah bagi mereka untuk cepat memahami serta menarik bagi mereka. Namun pada kenyataanya saat ini masih banyak pendidik masih menggunakan cara-cara lama yaitu mengunakan metode konvensional. Pada saat ini sudah menjadi sebuah tuntutan jika semua sekolah tak terkecuali TK yang menjadi tempat kegiatan pengabdian ini, untuk bisa menggunakan dan memanfaatkan komputer, dalam media pembelajarannya. Dengan semakin meningkatnya jumlah siswanya setiap tahunnya disekolah mitra dan bagi meningkatnya nilai status akreditasinya, perlu adanya perubahan sistem pembelajaran berbasis teknologi di sekolah Mitra tersebut, agar juga kualitas sekolah Mitra berbeda dengan TK-TK lain yang ada di kec. Mestong Kab. Muaro Jambi. Berdasarkan survey dan Hasil studi pendahuluan, ditemukan ada beberapa permasalahan di sekolah mitra, yaitu: Masih Banyak Guru-guru di sekolah mitra belum begitu mengerti dalam pengunaan Komputer khususnya aplikasi-aplikasi Multimedia untuk pendukung dalam pelaksanaan pembelajaran di sekolah TK Mitra, Sekolah Mitra pada saat ini belum memiliki infrastruktur TIK yang baik yaitu media pembelajaran di ruangan kelas seperti Infocus dan Komputer Laptop, Sekolah Mitra saat ini belum memiliki software-software multimedia untuk anak didiknya. Berdasarkan permasalahan yang dihadapi sekolah mitra tersebut yaitu TK Cahaya Bangsa Desa Nyogan. Kegiatan pengabdian IPTEK yang akan diberikan adalah 1) Penyuluhan tentang TIK sebagai sarana pembelajaran bagi guru di sekolah mitra, 2) Memberikan bantuan laptop dan infocus sebagai media pendukung pembelajaran, 3) Memberikan aplikasi multimedia untuk sekolah mitra. Tujuan Kegiatan ini dilakukan untuk: meningkatkan kemampuan guru-guru sekolah dan memudahkan guru mengajarkan anak didiknya di sekolah, dan dapat meningkatakan kualitas pembelajaran sekolah mitra ini. Kegiatan pengabdian ini diberikan dalam bentuk pelatihan. Metode yang digunakan adalah: ceramah, tanya jawab, sharing ide, praktik/latihan mengenai cara mengimplementasikan dan memelihara aplikasi multimedia tersebut. Lokasi kegiatan pengabdian diselenggarakan di Sekolah TK Cahaya Bangsa Desa Nyogan.
\end{abstract}

Kata Kunci: Multimedia, Anak Usia Dini, Guru, TK

\section{PENDAHULUAN}

Pada saat ini system Pendidikan merupakan salah satu interaksi pendorong terjadinya belajar. UNESCO menjabarkan empat pilar prinsip yang relevan dan mengemukakan dua prinsip yang relevan yang pertama, system pendidikan wajib memiliki 4 konsep yaitu "belajar untuk mengetahui (learning to know), belajar melakukan sesuatu (learning to do), belajar untuk hidup 
bersama (learning to life together) dan belajar jadi diri sendiri (learning to be), kedua belajar untuk seumur hidup (life long learning) (Mulyasa, 2006)”.

Di Usia TK (Taman Kanak-Kanak) di usia 4 s/d 6 tahun adalah dimana anak-anak memiliki rasa peka. Pada masa ini anak-anak akan merasakan sensitive untuk dapat menerima sesuatu yang baru untuk meningkatkan perkembangan segala potensi yang mereka miliki. "Masa peka merupakan masa terjadinya pematangan fungsi-fungsi fisik dan psikis yang siap merespon stimulasi yang diberikan oleh lingkungan (Martinis Y.\& Jamilah S.S., 2013)". kejadian yang didapat oleh anak-anak dari lingkungan sekitarnya, serta stimulus yang didapati dari orang dewasa, dapat mempengaruhi perilaku anak kedepannya. Untuk itu, perlu adanya langka-langkah yang harus dilakukan berupa aktivitas pendidikan dan pembelajaran yang sesuai dengan kebutuhan dan minat anak-anak agar di masa tumbuh kembangnya menjadi lebih baik kedepannya.

Perilaku anak-anak dibandingkan dengan orang dewasa memiliki karakteristik yang berbeda dalam berperilaku. Demikian juga dalam proses belajar, anak-anak juga memiliki karakteristik yang berbeda dibandingkan orang dewasa. Dalam merencanakan dan melaksanakan system pembelajaran bagi anak usia dini, karakteristik yang dimiliki seorang anak dalam cara belajar merupakan sebuah fenomena yang dapat dijadikan sebagai sebuah acuan. Adapun karakterisktik cara belajar anak. Menurut "Masitoh et.al, (2009) adalah: 1) anak belajar melalui bermain 2) anak belajar dengan cara membangun pengetahuanya 3) Anak belajar secara alamiah 4) Anak belajar paling baik jika apa yang di pelajari mempertimbangkan keseluruhan aspek pengembangan, bermakna, menarik, dan fungsional".

Sistem pembelajaran pada anak-anak memiliki system pembelajaran yang berbeda. System pembelajarannya bersifat auditori, visual maupun kinestik. Namun pada umumnya anak lebih tertarik belajar mengunakan metode dengan mengunakan multimedia sebagai medianya dikarenakan dengan cara ini lebih mudah bagi mereka untuk cepat memahami serta menarik bagi mereka. Namun pada kenyataanya saat ini masih banyak pendidik masih menggunakan cara-cara lama yaitu mengunakan metode konvensional. Dapat di ketahui bahwa peserta didik adalah penerima ilmu yang pasif sedangkan guru adalah orang yang memberikan informasi kepada peserta didik untuk itu seorang pendidik mengharapkan peserta didik dapat menghafal dan selalu mengingat dengan informasi yang telah diberikan. Cara pembelajaran yang demikian pada saat ini kurang menarik bagi peserta didik sehingga berdampak pada kebosanan dan ketidakpahaman peserta didik terhadap informasi yang telah diberikan oleh pendidik.

Multimedia dapat di artikan "sebagai penggunaan beberapa media yang berbeda untuk menggabungkan dan menyampaikan informasi dalam bentuk teks, audio, grafik, animasi dan video. Multimedia adalah kombinasi dari teks, foto, seni grafis, suara, animasi dan elemenelemen video yang dimanipulasi secara digital (Vaughan, 2006)". Agar tercapai tujuan system pendidikan nasional di Indonesia perlu adanya seperangkat kurikulum yang sesuai dengan situasi kemajuan teknologi pada saat ini sehingga dapat menunjang kepada kualitas dari anak didik pada saat ini.. Kurikulum merupakan suatu fasilitas dalam meraih tujuan pada satuan pendidikan yang disesuaikan dengan materi pembelajaran yang ada di sekolah (Turmudi, 2009).

Sekolah taman kanak-kanak yang dijadikan mitra dalam pelaksanaan pengabdian ini adalah TK Cahaya Bangsa yang berada didesa Nyogan, Kec. Mestong Kab. Muaro Jambi dengan alamat di Jl. Lintas Sungai Bahar Kec. Mestong, TK ini berdiri pada tahun 2016. Yang menjadi Ketua dari sekolah ini adalah Ibu Rosita Asrul dan kepala sekolahnya Ibu Siti Amelia. sekolah ini berdiri diatas tanah seluas $935 \mathrm{M}^{2}$. Pada saat ini TK Caya Bangsa memiliki jumlah kelas 2 kelas terbagi dalam 1 kelas untuk tingkat kelas TK A, 1 Kelas untuk tingkat kelas TK B. Untuk saat ini TK Cahaya Bangsa untuk jumlah peserta didiknya memiliki jumlah peserta 12 orang tiap kelas dan tingkatnya dan Guru 4 Orang, adapun tenaga administrasi di TK ini yaitu 
2 Orang. TK Cahaya Bangsa pada saat ini memfasilitas anak dari Suku Anak Dalam(SAD) untuk mendapatkan pendidikan di TK ini. Biaya pendidikan di sekolah ini sebesar Rp.30.000/anak didik. Untuk operasional sekolah. Sekolah mendapat dana bersumber dari dana APBD Kab. Muaro Jambi dan Dana Desa Nyogan kec, Mestong Kab. Muaro Jambi.
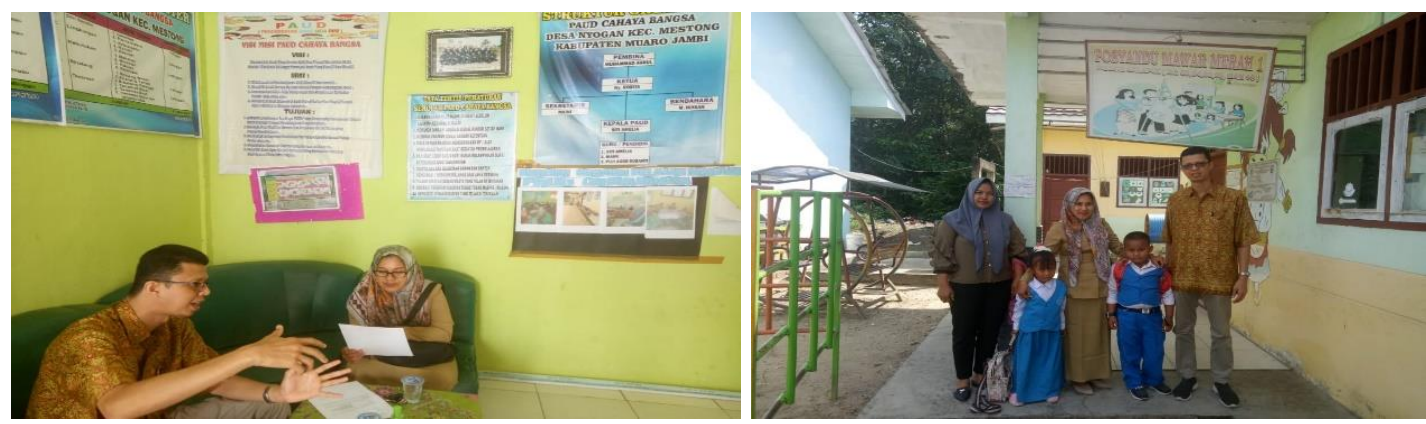

Gambar 1. Situasi TK Cahaya Bangsa Mitra Pengabdian

Pada saat ini, sistem pembelajaran yang digunakan di TK Cahaya Bangsa masih menggunakan cara-cara yang lama, yang mana peserta didik dalam memberikan materi dan penjelasan kepada peserta dididknya masih mengunakan tulisan dan gambar di papan tulis. Dengan adanya metode ini, Terkadang peserta didik masih sulit untuk dapat menerima dan menghafal materi yang diberikan oleh pendidik tersebut serta peserta didik sering merasa cepat bosan dengan materi yang disampaikan secara lisan oleh pendidik tersebut.

Pada saat ini sudah menjadi sebuah tuntutan jika semua sekolah tak terkecuali TK yang menjadi tempat kegiatan pengabdian ini, untuk bisa menggunakan dan memanfaatkan komputer,dalam media pembelajarannya. Dengan semakin meningkatnya jumlah siswanya setiap tahunnya disekolah mitra dan bagi meningkatnya nilai status akreditasinya, perlu adanya perubahan sistem pembelajaran berbasis teknologi di sekolah Mitra tersebut, agar juga kualitas sekolah Mitra berbeda dengan TK-TK lain yang ada di kec. Mestong Kab. Muaro Jambi. Penggunaan teknologi multimedia pada saat ini sudah menjadi sebuah tuntutan agar pembelajaran di sekolah TK lebih efektif lagi. Dengan system pembelajaran berbasis multimedia membuat anak-anak menjadi lebih focus lagi dengan materi yang disampaikan karena pada saat penyampaian anak merasa seperti bermain bukan belajar karena di usia ini anak-anak lebih cendrung suka bermain. System pembejaran seperti akan lebih efektif sesuai dengan apa yang menjadi harapan orang tua peserta didik dan pendidik dari sekolah tersebut serta pemerintah. Sistem pembelajaran yang baik pada anak usia dini menjadi sebuah perhatian khusus karena pada fase ini merupakan fondasi bagi anak didik untuk melanjutkan pendidikan berikutnya. Untuk menghasilkan generasi bangsa yang cerdas, berkarakter dan kreatif harus mulai dari sejak dininya.

Berdasarkan prasurvey dan hasil diskusi tim pengabdian dengan pengambil kebijakan di sekolah TK Mitra pengabdian. Maka didapati permasalahan utama yang dihadapi oleh sekolah tk mitra dalam pengabdian ini, yaitu :

1. Masih Banyak Guru-guru di sekolah mitra belum begitu mengerti dalam pengunaan

Komputer khususnya aplikasi-aplikasi Multimedia untuk pendukung dalam pelaksanaan pembelajaran di sekolah TK Mitra.

2. Sekolah Mitra pada saat ini belum memiliki infrastruktur TIK yang baik yaitu media pembelajaran di ruangan kelas seperti Infocus dan Komputer Laptop.

3. Sekolah Mitra saat ini belum memiliki software-software multimedia untuk anak didiknya.

Dengan adanya masalah tersebut, sekolah mitra membutuhkan pelatihan terhadap guruguru disekolah mitra bagi meningkatkan pengetahuan mereka akan pengunaan komputer 
untuk proses peengajaran berbasis multimedia, dan sekolah mitra perlu pendampingan dalam peningkatan infrastruktur TIK di sekolah seperti penyediaan infocus dan Komputer Laptop serta software-software berbasis multimedia khusus untuk peserta didiknya. Dengan diadakan pengabdian ini, diharapkan oleh pihak sekolah dapat membantu sekolah mitra dalam meningkatkan kualitas mutu pendidikan anak didiknya, guru, maupun masyarakat yang ada di desa Nyogan kec. Mestong khsusunya masyarakat SAD.

\section{TARGET DAN METODE PELAKSANAAN}

Target utama dari pelaksanaan pengabdian ini adalah bagaimana cara pengunaan aplikasi multimedia bagi anak usia dini dan meningkatnya kualitas guru-guru yang berbasis TIK dalam pengajaran di sekolah tempat pelaksana pengabdian sehingga dengan adanya kegiatan pengabdian ini dapat meningkatkan kualitas sekolah khusus dalam hal peningkatan metode pembelajaran didalam kelas bagi peserta didiknya dan peningkatan nilai akreditasi sekolah Mitra serta keinginan masyarakat didesa Nyogan sesuai dengan apa yang telah dianalisis secara sederhana pada pendahuluan. Adapun bentuk output dari pelaksanaa pengabdian IPTEK ini adalah Metode dalam meningkatkan kualitas guru sekolah khususnya di sekolah TK dan Pelatihan pengunaan teknologi tepat guna berupa Aplikasi Multimedia bagi anak usia dini dan bantuan sarana pembelajara berbasis multimedia.

Innovasi IPTEK dalam program Pengabdian IPTEK ini berupa bentuk Aplikasi Multimedia bagi anak usia dini untuk sekolah mitra yang berbentuk Mobile mudah dan dapat diakses dari mana-mana saja; Unik dari bentuk tampilannya dan Menarik sehingga dapat mudah digunakan oleh guru dari sekolah mitra.

Taget luaran yang diharapkan dari kegiatan pengabdian penerapan Iptek terdiri dari 3 hal Yaitu.

1. Metode dalam meningkatkan kualitas guru-guru dalam pembelajaran dengan mengunakan TIK

2. Publikasi yang akan dilakukan dalam Jurnal Ilmiah dan Seminar Nasional.

3. Produk dalam Bentuk Aplikasi Aplikasi Multimedia bagi anak usia dini dan 1 unit Laptop dan infocus untuk Sekolah mitra.

Berikut Ini bentuk-bentuk luaran dari pengabdian ini yaitu Aplikasi Multimedia bagi anak usia dini dan 1 Unit Ladtop yang akan di berikan kepada sekolah Mitra Pengabdian Ini.
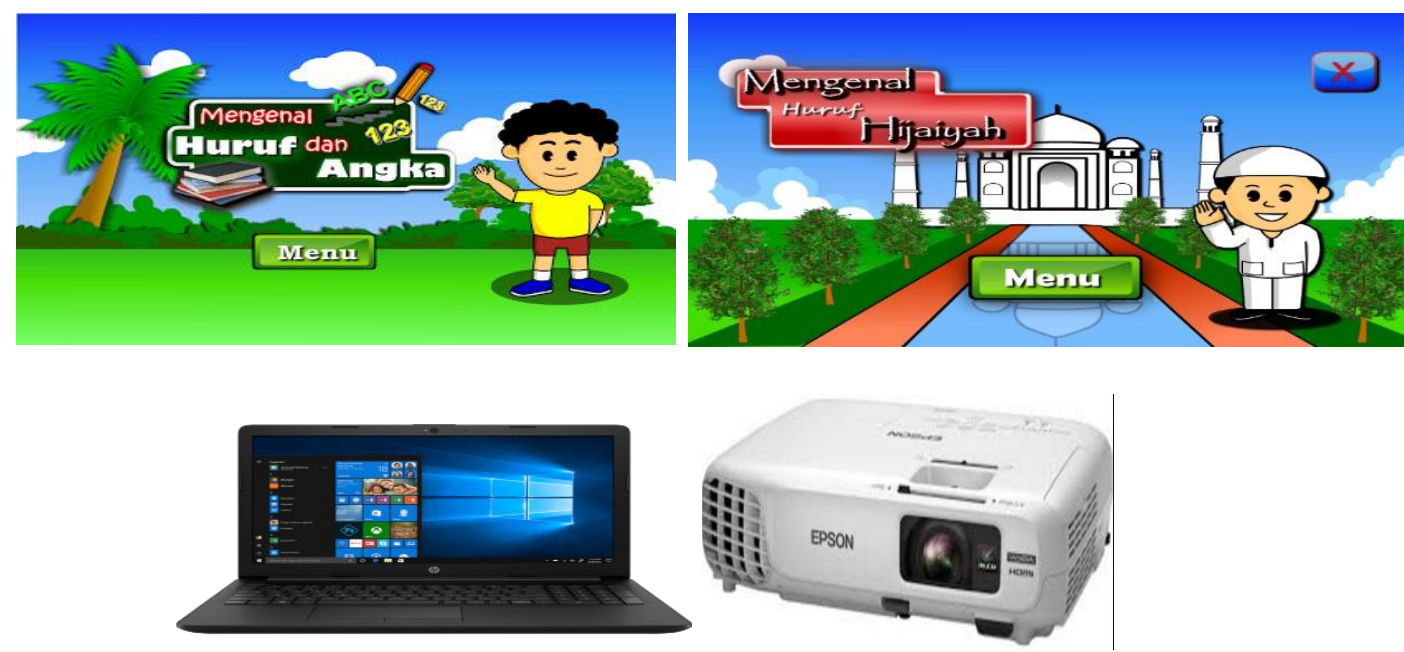

Gambar 2. Bentuk Aplikasi Multimedia Bagi Anak Usia dini Yang Diberikan dan 1 Unit Laptop serta Infocus untuk perangkat Sistem kepada Sekolah Mitra 
Berdasarkan permasalahan yang terjadi pada mitra tersebut, Metode pelaksanaan pada pengabdian IPTEK kepada mitra ini, dimulai dari proses identifikasi kebutuhan dari mitra,, pengenalan TIK, demonstrasi pengunaan aplikasi multimedia, pelatihan serta Evaluasi Adapun langkah-langkah yang dilakukan dalam pengabdian ini adalah sebagai berikut:

Tahap awal untuk meningkatkan pengetahuan Guru-Guru dalam Pengunaan TIK dalam Proses Pembelajaran

Pada tahap ini dilakukan beberapa sub kegiatan antara lain:

1. Melakukan survey awal untuk mengetahui pengetahuan peserta khususnya guru-guru di Sekolah Mitra. Kegiatan ini dilakukan dengan melakukan wawancara secara langsung kepada guru-guru tentang pengunaan TIK yang diketahui baik yang diperoleh dari hasil belajar maupun dari pengalaman secara langsung maupun tidak langsung meliputi: prinsip, metode, dan prosedur dalam pengunaan TIK dalam proses pembelajaran

2. Pemberian materi TIK dalam bentuk ceramah dan praktek (pengenalan Aplikasi Microsoft Office dan Internet) untuk proses pembelajaran dengan cara ceramah

3. Evaluasi akhir dari kegiatan ini dilakukan dalam rangka untuk mengetahui tingkat pemahaman mitra terhadap materi yang telah diberikan.

\section{Tahap meningkatkan pengetahuan Guru-Guru dalam Pengunaan Aplikasi Multimedia Bagi Anak Usia Dini}

Pada tahapan kedua ini dilakukan beberapa aktivitas antara lain:

1. Melakukan survey awal untuk dapat mengetahui tingkat pengetahuan peserta khususnya guru-guru di Sekolah Mitra. Kegiatan ini dilakukan dengan melakukan wawancara sera langsung kepada guru-guru tentang aplikasi multimedia untuk anak usai dini yang mereka ketahui selama ini baik hasil pelatihan maupun secara langsung maupun tidak yang meliputi: "prinsip, metode, dan prosedur" dalam pengunaan Aplikasi Multimedia dalam proses pembelajaran

2. Pemberian materi Aplikasi Multimedia Bagi anak usai dini untuk proses pembelajaran dengan cara ceramah

3. Evaluasi akhir dilaksanakan dengan tujuan untuk mengetahui secara pasti tingkat pemahaman guru terhadap materi yang telah diberikan.

\section{Tahap Demontrasi Pengunaan Aplikasi Multimedia Bagi Anak Usia Dini}

Pada tahap pelaksanaan aktivitas ini dilakukan beberapa kegiatan, yaitu:

1. Memberikan bantuan berupa Laptop dan Infocus serta aplikasi Multimedia untuk anak usia dini secara langsung kepada kepala sekolah yang disaksikan oleh guru di sekolah mitra.

2. Pemberian materi cara install Aplikasi Multimedia Bagi anak usai dini untuk proses pembelajaran dengan cara praktek dan ceramah

3. Evaluasi akhir dilaksanakan dengan tujuan untuk mengetahui secara pasti tingkat pemahaman guru terhadap materi yang telah diberikan.

Hubungan masalah dengan metode pelaksanaan kegiatan yang ditawarkan pada pengabdian IPTEK pada Sekolah TK ini, di Desa Nyogan di Kec Mestong, Kab. Muaro Jambi juga disajikan pada Tabel 1. 
Tabel 1. Metode yang Ditawarkan dalam Pengabdian Penerapan IPTEK pada TK Cahaya Bangsa Desa Nyogan Kec. Mestong, Kab. Ma. Jambi

\begin{tabular}{|c|c|c|c|}
\hline Masalah & Permasalahan & Tujuan & $\begin{array}{l}\text { Solusi yang ditawarkan } \\
\text { (Metode) }\end{array}$ \\
\hline $\begin{array}{l}\text { Pendidik/guru } \\
\text { di sekolah } \\
\text { mitra belum } \\
\text { memahami } \\
\text { pengunaan TIK } \\
\text { untuk proses } \\
\text { pembelajaran }\end{array}$ & $\begin{array}{l}\text { Rendahnya } \\
\text { pengetahuan dan } \\
\text { keterampilan } \\
\text { pendidik tentang } \\
\text { Pemanfaatan } \\
\text { TIK untuk } \\
\text { proses pembelajaran }\end{array}$ & $\begin{array}{l}\text { Meningkatkan } \\
\text { pengetahuan dan } \\
\text { keterampilan } \\
\text { pendidik di } \\
\text { sekolah Mitra }\end{array}$ & $\begin{array}{l}\text { 1. Penyuluhan dengan } \\
\text { metode ceramah dan } \\
\text { diskusi } \\
\text { 2. Demonstrasi } \\
\text { pengunaan TIK } \\
\text { dalam proses } \\
\text { pembelajaran } \\
\text { Mengunakan } \\
\text { M.Office(Power } \\
\text { Point) }\end{array}$ \\
\hline $\begin{array}{l}\text { Sekolah TK } \\
\text { belum } \\
\text { memiliki saran } \\
\text { pendukung } \\
\text { dalam } \\
\text { menerapkan } \\
\text { pembelajaran } \\
\text { berbasis } \\
\text { multimedia } \\
\end{array}$ & $\begin{array}{l}\text { Sekolah belum } \\
\text { perangkat } \\
\text { pendukung } \\
\text { untuk proses } \\
\text { pembelajaran } \\
\text { berbasis } \\
\text { multimedia }\end{array}$ & $\begin{array}{l}\text { Menyediakan } \\
\text { alat pendukung } \\
\text { bagi sekolah } \\
\text { mitra untuk } \\
\text { pembelajaran } \\
\text { berbasis } \\
\text { multimedia }\end{array}$ & $\begin{array}{l}\text { 1. Memberikan } \\
\text { bantuan satu unit } \\
\text { laptop yang telah } \\
\text { diinstall dengan } \\
\text { Aplikasirrs } \\
\text { informasi desa untuk } \\
\text { kantor desa }\end{array}$ \\
\hline $\begin{array}{l}\text { Sekolah TK } \\
\text { mitra belum } \\
\text { software yang } \\
\text { akan } \\
\text { digunakan } \\
\text { untuk proses } \\
\text { pembelajaran } \\
\text { berbasis } \\
\text { multimedia }\end{array}$ & $\begin{array}{l}\text { Sekolah mitra } \\
\text { belum memiliki } \\
\text { softaware } \\
\text { multimedia } \\
\text { untuk } \\
\text { pembelajaran } \\
\text { anak usia dini }\end{array}$ & $\begin{array}{l}\text { Menyediakan } \\
\text { software yang } \\
\text { digunakan untuk } \\
\text { proses } \\
\text { pembelajaran } \\
\text { berbasis } \\
\text { multimedia }\end{array}$ & $\begin{array}{l}1 . \quad \text { Memberikan } \\
\text { software-software untuk } \\
\text { sekolah mitra untuk } \\
\text { pembelajaran berbasis } \\
\text { multimedia }\end{array}$ \\
\hline
\end{tabular}

Tahapan pelaksanaan kegiatan pengabdian IPTEK pada di sekolah TK di "Desa Nyogan kec. Mestong, Kab. Muaro Jambi" disusun dengan pertimbangan utama agar solusi/metode yang direncanakan dalam menyelesaikan sumber permasalahan yang dihadapi pihak sekolah dapat berjalan sesuai dari tujuan utama dari pengabdian ini.

\section{PEMBAHASAN}

Saat ini kegiatan sudah berlangsung, prioritas utama yang sudah dilakukan adalah mempersiapkan produk-produk berbasis teknologi yaitu media pembelajaran berbasis multimedia bagi anak usia dini. Selanjutnya, sudah mempersiapkan sarana pendukung berupa media yang dapat digunakan, selanjutnya telah dilakukan kegiatan berupa pelatihan dan demonstrasi langsung dilapangan dihadapan pengelolah TK mitra.

Secara lebih rinci tahapan kerja pelaksanaan kegiatan dapat dilihat pada tabel 2 . dibawah ini. 
Tabel 2. Tabel Tahapan Kerja Pelaksanaan Kegiatan

\begin{tabular}{|c|c|c|c|c|}
\hline $\begin{array}{l}\mathbf{N} \\
\mathbf{o}\end{array}$ & $\begin{array}{c}\text { Jenis } \\
\text { Kegiatan }\end{array}$ & Bentuk Kegiatan & Tujuan & Pelaksanaan \\
\hline 1 & $\begin{array}{l}\text { Penerapan } \\
\text { Iptek Bagi } \\
\text { Peningkatan } \\
\text { Kapasitas } \\
\text { Dan Kualitas } \\
\text { Guru Tk Di } \\
\text { Desa } \\
\text { Nyogan } \\
\text { Melalui } \\
\text { Sistem } \\
\text { Pembelajara } \\
\text { n Berbasis } \\
\text { Multimedia } \\
\end{array}$ & $\begin{array}{ll}\text { a. } & \text { Pengurusan } \\
\text { surat } \\
\text { perizinan }\end{array}$ & & $\begin{array}{l}\text { Sudah } \\
\text { dilaksanaka } \\
\mathrm{n}\end{array}$ \\
\hline & $\begin{array}{l}\text { Penerapan } \\
\text { Iptek Bagi } \\
\text { Peningkatan } \\
\text { Kapasitas Dan } \\
\text { Kualitas Guru } \\
\text { Tk Di Desa } \\
\text { Nyogan } \\
\text { Melalui Sistem } \\
\text { Pembelajaran } \\
\text { Berbasis } \\
\text { Multimedia }\end{array}$ & $\begin{array}{ll}\text { b. } & \text { Survei } \\
& \text { pendahulua } \\
\mathrm{n}\end{array}$ & $\begin{array}{l}\text { Diperlukan untuk } \\
\text { mendapatkan } \\
\text { informasi apakah } \\
\text { sumber daya } \\
\text { yang dimiliki } \\
\text { oleh mitra telah } \\
\text { memadai atau } \\
\text { Tidak untuk } \\
\text { digunakan pada } \\
\text { fase } \\
\text { Pengembangan } \\
\text { selanjutnya } \\
\text { Mengetahuisebab } \\
\text { dan akibat yang } \\
\text { ditimbulkan dari } \\
\text { sistem yang } \\
\text { sedang berjalan } \\
\text { Mengetahui } \\
\text { keinginan/ apa } \\
\text { yang diharapkan } \\
\text { oleh mitra }\end{array}$ & $\begin{array}{l}\text { Sudah } \\
\text { dilaksanaka } \\
\text { n }\end{array}$ \\
\hline & & $\begin{array}{ll}\text { c. } & \text { Rakor tim } \\
& \text { pelaksana dan } \\
\text { pengurus } \\
\text { (Mitra) }\end{array}$ & & $\begin{array}{l}\text { Sudah } \\
\text { dilaksanaka } \\
\mathrm{n}\end{array}$ \\
\hline & & $\begin{array}{ll}\text { d. } & \begin{array}{l}\text { Penyusunan } \\
\text { rencana } \\
\text { kerja }\end{array} \\
\end{array}$ & & $\begin{array}{l}\text { Sudah } \\
\text { dilaksanaka } \\
\mathrm{n}\end{array}$ \\
\hline & & $\begin{array}{l}\text { e. Perancangan } \\
\text { dan } \\
\text { Pembuatan } \\
\text { Produk- }\end{array}$ & $\begin{array}{l}\text { Menterjemahka } \\
\text { n keinginan } \\
\text { mitra ke Dalam } \\
\text { aplikasi } \\
\text { Multimedia. }\end{array}$ & $\begin{array}{l}\text { Sudah } \\
\text { dilaksanakan } \\
\text { (Dalam Proses } \\
\text { Penyempurnaan) }\end{array}$ \\
\hline
\end{tabular}




\begin{tabular}{|c|c|c|c|c|}
\hline & & $\begin{array}{l}\text { Produk } \\
\text { Teknologi }\end{array}$ & & \\
\hline & & d. Evaluasi awal & & $\begin{array}{l}\text { Sudah } \\
\text { dilaksanakan }\end{array}$ \\
\hline \multirow[t]{5}{*}{2.} & $\begin{array}{l}\text { Penyuluhan } \\
\text { tentang TIK } \\
\text { sebagai sarana } \\
\text { pembelajaran } \\
\text { bagi guru di } \\
\text { sekolah mitra }\end{array}$ & $\begin{array}{ll}\text { g. } & \text { Penyuluhan dan } \\
& \text { pengenalan TIK } \\
& \text { sebagai sarana } \\
& \text { Pembelajaran }\end{array}$ & $\begin{array}{l}\text { Memperkenalkan } \\
\text { serta } \\
\text { menjelaskan } \\
\text { kepada guru di } \\
\text { sekolah mitra } \\
\text { manfaat TIK } \\
\text { untuk media } \\
\text { pembelajaran }\end{array}$ & $\begin{array}{l}\text { Sudah } \\
\text { dilaksanakan }\end{array}$ \\
\hline & & $\begin{array}{ll}\text { h. } & \text { Bimbingan } \\
& \text { Aplikasi } \\
& \text { Multimedia } \\
& \text { Pembelajaran } \\
\end{array}$ & & $\begin{array}{l}\text { Sudah } \\
\text { dilaksanakan }\end{array}$ \\
\hline & & $\begin{array}{ll}\text { i. } & \text { Bimbingan } \\
& \text { Aplikasi } \\
& \text { Multimedia } \\
& \text { Pembelajaran } \\
\end{array}$ & & $\begin{array}{l}\text { sudah } \\
\text { dilaksanakan }\end{array}$ \\
\hline & & j. $\quad$ Evaluasi akhir & & $\begin{array}{l}\text { sudah } \\
\text { dilaksanakan }\end{array}$ \\
\hline & & $\begin{array}{ll}\text { k. } & \text { Bimbingan } \\
& \text { lanjutan } \\
& \text { pengunaan } \\
\text { Aplikasi Media } \\
\text { Pembelajaran }\end{array}$ & & $\begin{array}{l}\text { sudah } \\
\text { dilaksanakan }\end{array}$ \\
\hline 3 & $\begin{array}{l}\text { Memberikan } \\
\text { Bantuan } \\
\text { Laptop dan } \\
\text { Infocus } \\
\text { sebagai sarana } \\
\text { pembelajaran } \\
\text { berbasis } \\
\text { multimedia }\end{array}$ & $\begin{array}{l}\text { 1. Memberikan } 1 \\
\text { Unit Laptop dan } \\
1 \text { Unit Infocus }\end{array}$ & $\begin{array}{l}\text { Sebagai media } \\
\text { pembelajaran di } \\
\text { sekolah Mitra }\end{array}$ & $\begin{array}{l}\text { Sudah } \\
\text { Dilaksanakan }\end{array}$ \\
\hline \multirow[t]{3}{*}{4} & $\begin{array}{l}\text { Pembuatan } \\
\text { Laporan }\end{array}$ & $\begin{array}{ll}\mathrm{m} & \text { Pembuatan } \\
\cdot & \text { Laporan } \\
& \text { Kemajuan } \\
\end{array}$ & & $\begin{array}{l}\text { sudah } \\
\text { dilaksanakan }\end{array}$ \\
\hline & & $\begin{array}{ll}\text { n. } & \text { Pembuatan } \\
& \text { Laporan Akhir }\end{array}$ & & $\begin{array}{l}\text { sudah } \\
\text { dilaksanakan }\end{array}$ \\
\hline & & $\begin{array}{ll}\text { o. } & \text { Seminar hasil } \\
& \text { Pengabdian }\end{array}$ & & $\begin{array}{l}\text { sudah } \\
\text { dilaksanakan }\end{array}$ \\
\hline
\end{tabular}




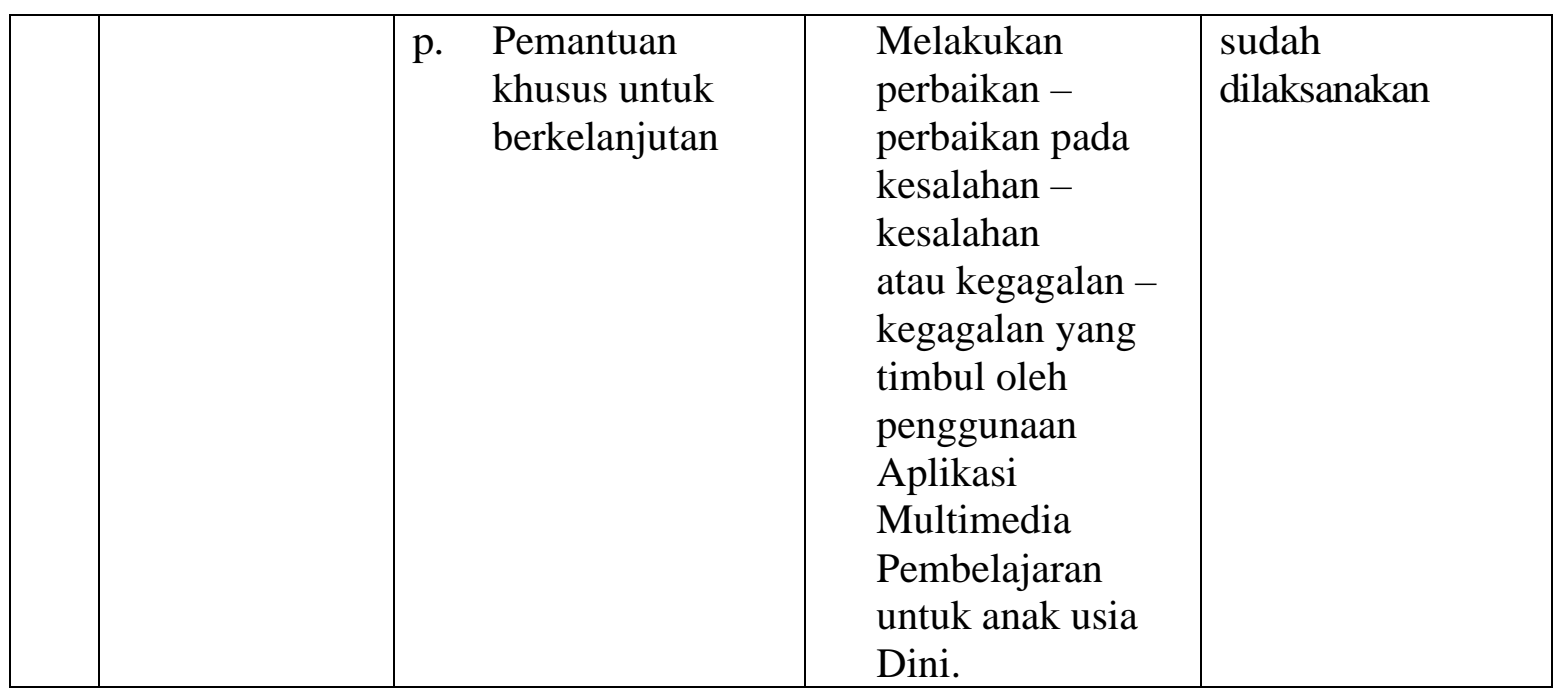

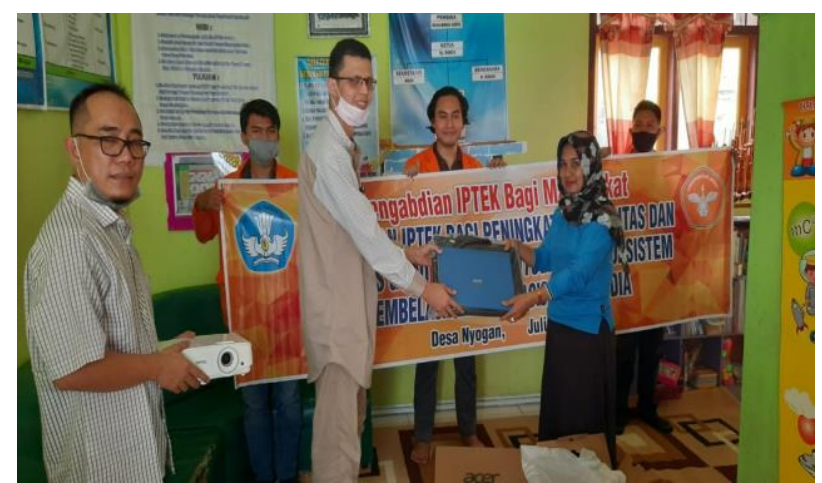

Gambar 3. Kegiatan pemberian bantuan aplikasi dan perangkat pembelajaran di Sekolah Mitra

\section{KESIMPULAN}

Kesimpulan sementara dari beberapa kegiatan pengabdian yang telah dilaksanakan adalah adanya motivasi dari para guru di sekolah mitra untuk memanfaatkan sistem multimedia diberikan dalam rangka meningkatkan mutu pendidikan dan lulusan dari sekolah mitra, dimana sebelumnya pembelajaran di sekolah mitra dilakukan secara manual saat ini sudah dapat dilakukan dengan menggunakan sistem terkomputerisasi.

Namun, agar kegiatan ini berjalan lebih baik lagi. Perlu adanya peranan stakeholder khusus dinas pendidikan Kab. Muaro Jambi yang terkait dengan pengembangan pengetahuan guru-guru di sekolah mitra khususnya pengetahuan akan TIK sehingga kedepannya proses pembelajaran di sekolah tersebut dapat berjalan sesuai dengan apa yang dinginkan oleh pihak masyarakat khususnya masyarakat didesa Nyogan Kec. Mestong Kab. Muaro Jambi.

\section{UCAPAN TERIMAKASIH}

Terima kasih kami ucapkan kepada Rektor, Ketua Lembaga Penelitian dan pengabdian Universitas Jambi atas pendanaan kegiatan pengabdian ini sebagi bentuk pembinaan dosen di Perguruan Tinggi Universitas Jambi sehingga pengabdian ini dapat terselenggara dengan baik serta atas dukungan dan arahannya dalam kegiatan pengabdian ini. Terima kasih pula kami ucapakan kepada Kepala sekolah TK Cahaya Bangsa yang telah memberikan ijin untuk dapat melaksanakan kegiatan pengabdian masyarakat ini. 


\section{DAFTAR PUSTAKA}

Martinis, Y., \& Jamilah, S. S. (2013). Panduan PAUD Pendidikan Anak Usia Dini. Jakarta: Referensi

Mulyasa, E (2011). Kurikulum Tingkat SatuanPendidikan. Bandung: PT. Remaja Rosdakarya. Masitoh et.al, (2009). Pendekatan Belajar Aktif di Taman Kanak-kanak. Departemen Pendidikan Nasional, Jakarta.

Turmudi, (2009). Pemecahan Masalah Matematika. Diakses dari laman web tanggal 18 Feb 2020

dari: http://file.upi.edu/Direktori/FPMIPA/JUR._PEND._MATEMATIKA/19610112198703 1TURMUDI/F 20-PEMECAHAN_MASALAH_MATEMATIKA-1-11-2008.pdf. (Diakses tanggal 18 Feb 2020)

Vaughan, Tay. 2006. Multimedia: Making It Work,Edisi 6. Yogyakarta: ANDI 